\title{
Introduction of measles into a highly immunised West African community: the role of health care institutions
}

\author{
PETER AABY,${ }^{1}$ JETTE BUKH, ${ }^{1}$ IDA MARIA LISSE, ${ }^{2}$ AND ARJON J SMITS ${ }^{2}$ \\ From the Institute of Ethnology and Anthropology, ${ }^{1}$ University of Copenhagen, and Department of Pathology, ${ }^{2}$ \\ Gentofte Hospital, Copenhagen, Denmark
}

SUMMARY In an urban area of Guinea-Bissau, where more than $80 \%$ of the children have been vaccinated, measles continues to be a major cause of child mortality. Compared with the period before the introduction of vaccination, more cases occur outside the community, while more cases within the district are now guests and newcomers. Half of the new introductions of measles into the community and $30 \%$ of the measles deaths can be traced back to the paediatric ward. Contact with health care institutions plays an important role in the transmission of measles, particularly among the youngest children. This consequence of health care may be avoidable, however, since several studies suggest that sick children can be vaccinated safely and effectively.

There has been a growing interest in controlling and even eradicating measles. ${ }^{1-3}$ Effective strategies for the control or eradication of measles in developing countries require epidemiological studies of disease transmission in different social environments. This study describes the experience from an urban district in Guinea-Bissau. Despite a high level of immunisation, measles has continued to be a major cause of deaths registered in the community. An attempt was made to find out how measles was introduced into the district.

\section{Subjects and methods}

\section{BA C KGROUN D}

Since December 1978, Bandim, a district in the capital of Guinea-Bissau with a population of 6217 persons, has been the site of a child nutrition and health project. A health centre arranges for examinations of all children under 3 years of age at three-month intervals. Local assistants make inquiries about children who do not appear for examination. A recensus in 1982 indicates that virtually all deaths in the age group are found by this method.

During 1979, a very severe measles epidemic occurred in the community. The case fatality rate for children under 5 years of age was $21 \%(74 / 356)$. As a consequence, a measles vaccination campaign was implemented in December 1979. From late 1980, immunisations have been carried out in connection with the quarterly examinations.

\section{MEASLES INCIDENCE}

In connection with examinations and vaccination campaigns, mothers are asked if anybody in their house or neighbourhood has contracted measles since the introduction of measles vaccination. Furthermore, during a recensus in December 1981-February 1982, information on measles immunity was obtained for all children under 10 years of age. Information from these sources was checked in interviews with adults in each house where measles was said to have occurred. Questions were asked about how the children had caught measles. The first child to get sick in a house is considered an index case. Children getting sick seven or more days after an index cases are assumed to be secondary cases infected in the house. ${ }^{4}$

The cases to be analysed here consist of all individuals having measles in Bandim between January 1980 and February 1982 as well as those from Bandim who contracted measles while outside the district. Comparison is made with the period before the introduction of measles vaccination. ${ }^{4}$

DIAGNOSIS AND " MEASLES DEATH"

Experience from Bandim suggests that measles is not overdiagnosed by lay people. "Measles death" has been defined as any death occurring within a month 
of an attack of the disease. ${ }^{4}$ There were 23 such deaths. Lay diagnoses sometimes indicate that deaths in the second and third months after an attack of measles were due to measles. Four children died in the second and third months after an attack of measles.

\section{Results}

In spite of an 80 to $90 \%$ vaccination coverage, ${ }^{5}$ many cases occurred in the period under surveillance (table $1)$. In contrast with 1979 , when only $5 \%(21 / 459)$ had measles outside Bandim, 12\% of cases occurred outside the district in $1980-2\left(\mathrm{p}<0.001 ; \chi^{2}=11 \cdot 9\right)$. Another result of the vaccination coverage was that guests and newcomers not previously registered in Bandim in the period 1980-2 constituted 30\% $(49 / 161)$ of the cases whereas they had only been $16 \%(72 / 459)$ in $1979\left(\mathrm{p}<0.001 ; \chi^{2}=16 \cdot 5\right)$.

In $1980-2,15 \%(82 / 531)$ of Bandim houses were affected by measles (table 1). In 34 cases, the source of infection was contact with a measles case in a neighbouring house, in school or at the market. Most of the 20 cases where the source was unknown presumably belong to the same category. There was no concentration of cases in houses bordering the neighbouring districts. These adjacent areas where little vaccination has been carried out have therefore not been particularly important as sources of introduction of measles.
In 24 instances, measles was introduced from another area to Bandim (table 1). Ten sick children had measles at the hospital (2) or shortly after returning from the hospital (8), and three healthy children contracted measles during a visit to the hospital. Health institutions were thus responsible for half of the foreign introductions (13/24). Among the introductions, the hospital accounted for $86 \%$ $(12 / 14)$ of the index cases under 2 years of age (table 2).

Since children were vaccinated from the age of 6 months during the initial campaigns, it could be feared that vaccine failures would contribute to the introduction of measles cases. However, there were only $17 \%(4 / 24)$ vaccinated children among the foreign introduction cases whereas $36 \%$ of other cases had been vaccinated against measles. All four vaccinated introduction cases contracted the disease during hospitalisation. Five of the other introductions from the hospital were 5-9 months old and had not yet been vaccinated.

The 11 persons who introduced measles from areas other than the hospital had not been protected by vaccination because they were guests (6) or were tog old (4) or too young (1) to be included in the regulam measles vaccination programme.

In the 1980-2 period, 43\% (10/23) of death occurred among guests and newcomers, whereas such deaths had constituted only $12 \%(9 / 77)$ in 1978 $(p=0.003$; Fischer's exact test). Among the 1

Table 1 Deaths and cases of measles by source of infection, Bandim, Guinea-Bissau, January 1980 to February 1982

\begin{tabular}{|c|c|c|c|}
\hline Source of infection & No. of houses affected, introductions & Deaths/no. ill & Case fatalityrate forchildren $<5 y r$ (no.ill) \\
\hline Measles outside Bandim & & $2 / 20$ & $13 \cdot 3 \%(15)$ \\
\hline \multicolumn{4}{|l|}{ Internal transmissions } \\
\hline Neighbours, school, market & 34 & $5 / 51$ & $10 \cdot 0 \%(40)$ \\
\hline Health centre in Bandim & 4 & $0 / 4$ & $0.0 \%(4)$ \\
\hline Unknown source & 20 & $2 / 33$ & $7 \cdot 4 \%(27)$ \\
\hline \multicolumn{4}{|l|}{ Foreign introductions } \\
\hline Guests and newcomers & 6 & $7 / 19$ & $30 \cdot 0 \%(15)$ \\
\hline Contact outside Bandim & 8 & $0 / 14$ & $0.0 \%(6)$ \\
\hline Paediatric hospital & 10 & $7 / 20$ & $29 \cdot 4 \%(17)$ \\
\hline Total & 82 & $23 / 161$ & $15 \cdot 3 \%(124)$ \\
\hline
\end{tabular}

Table 2 Index cases by age and source of infection, Bandim, Guinea-Bissau, January 1980 to February 1982

\begin{tabular}{|c|c|c|c|c|c|}
\hline \multirow{2}{*}{$\begin{array}{l}\text { Age of } \\
\text { Infection (mth) }\end{array}$} & \multicolumn{2}{|l|}{ Internal transmissions } & \multicolumn{2}{|l|}{ Foreign introductions } & \multirow[b]{2}{*}{ Total } \\
\hline & Neighbourhood, unknown source & Health centre & Contact outside Bandim, guests & Hospital, visits to hospital & \\
\hline $\begin{array}{l}5-23 \\
24-59 \\
60+\end{array}$ & $\begin{array}{r}26 \\
20 \\
8\end{array}$ & 4 & $\begin{array}{l}2 \\
2 \\
7\end{array}$ & $\begin{array}{r}12 \\
1\end{array}$ & $\begin{array}{l}44 \\
23 \\
15\end{array}$ \\
\hline Total & 54 & 4 & 11 & 13 & 82 \\
\hline
\end{tabular}


Bandim children who died of measles, one had been vaccinated at 8 months of age, three at 9 months, and one at 28 months. Three children were too young (7-8 months) to be vaccinated when they caught measles and died. Three other unvaccinated children were aged 9,10 , and 14 months when they contracted measles. Two older children who died had not been vaccinated because they had an undocumented history of prior vaccination.

Of all measles deaths, three were among children who had been hospitalised and four occurred in the houses to which hospitalised children brought measles. Three more of those children who had been hospitalised (2) or had caught measles from such children (1) died in the second or third month after the measles attack. The role of the paediatric ward is illustrated in the following case report.

\section{CASE REPORT}

House 2-34 is of good standard with concrete floor and corrugated iron roof. The 10 rooms are divided between several households.

Household I CC, a girl aged 12 months, who had been vaccinated against measles at 9 months, was admitted to hospital in early January 1982. She developed measles a few days after returning from the hospital and died on 27 January 1982. An older sibling, JC, 5 years old, developed measles on 5 February 1982 and died five days later.

Household II BM, a boy aged 9 months, was admitted to hospital at the same time as CC from household I. BM developed measles in late January 1982, six days after returning from the hospital. A nurse from Bandim's health centre treated BM at home on February 10 and on the days following. He died on 1 March.

Household III BC, a boy aged 11 months, was seen with a severe attack of measles on 18 February 1982. He died on 12 May.

Household IV AG, a girl aged 14 years, was found to have measles on 18 February. She survived.

\section{Discussion}

There are several indications that vaccination has changed the epidemiology of measles infection in Bandim. Compared with the period before the introduction of vaccination, more children contracted measles outside the district and a much larger proportion of the cases detected in Bandim itself were guests and newcomers.

One distinctive feature of measles epidemiology in developing countries is the young age of infection. Contact at health care institutions may play an important role for the early transmission of infection. A study from Yaoundé, Cameroun, indicated that among 69 children with measles in the age group 6-23 months old, $42 \%$ (29) had been exposed to measles at a health centre. ${ }^{6}$ In Bandim, the health centre apparently played a minor role in measles transmission. This may be due to the fact that the health centre has no waiting room, and children with measles are brought for consultation mainly in the convalescent phase. However, the paediatric ward of the central hospital, which has no possibility of enforcing isolation, plays an important role in the transmission of measles in the community, particularly for children under 2 years of age.

In 1979, before the introduction of measles vaccination, contact with health institutions accounted for only 7\% (31/459) of the cases compared with $12 \%$ in $1980-2\left(\mathrm{p}<0.05 ; \chi^{2}=5 \cdot 1\right)$. The percentage of measles deaths due to contact with health institutions increased from 7\% (5/77) in 1979 to $30 \%(7 / 23)$ in the last period $(p=0.01$; Fischer's exact test). With a high coverage of the immunisation programme, paediatric ward and health centres are likely to become increasingly important as sources of measles transmission.

Several studies have noted that measles contracted at the hospital is severe, often with a high case fatality rate. $^{7-10}$ However, introductions of measles in the community via the paediatric ward may contribute more to measles inflicted child mortality than those cases occurring during hospitalisation. Not less than $37 \%(10 / 27)$ of all who died within three months of a measles attack had caught the disease at the hospital or through contact with someone returning from a stay in hospital. The fact that children died of infection they had caught in the ward contributes much to the popular fear of hospitals.

The importance of health institutions in measles transmission can probably be reduced. There has been some reluctance to vaccinate sick children, ${ }^{10} 11$ and a few reports of children dying shortly after vaccination $^{10}$ have suggested that measles vaccination may kill severely malnourished and immunodeficient children. However, all studies of a large number of patients indicate that sick and malnourished children can be vaccinated safely and effectively against measles. ${ }^{2814-18}$ A control study concluded that measles vaccination almost completely prevented cross infections with measles and did not constitute a significant risk to severely sick children. ${ }^{8}$ Another study ${ }^{18}$ reported a highly significant reduction in mortality from a level of $17 \%$ $(104 / 600)$ in the year preceding measles immunisation to $8 \%(51 / 654)$ in the year after measles vaccination was given on admission, to all children aged 6-36 months $\left(p<0 \cdot 001 ; \chi^{2}=26 \cdot 3\right)$. Considering both the risk of contracting measles during hospitalisation and the risk of transmitting the 
disease to individuals outside the hospital, there are good reasons to study further the possibility of routine immunisation on admission to paediatric wards in developing countries, at least when there are cases of measles in the ward.

Priorities in measles vaccination programmes have recently been discussed. ${ }^{1219}$ An urban area such as Bandim will often be the source of infections for outbreaks in rural areas. ${ }^{20}$ This means that priority should be given to regular vaccination programmes in towns. ${ }^{2}$ Within the city, paediatric wards and clinics for sick children may be important places for measles transmission. They should be better controlled.

Data presented in this paper were collected in a study initiated by the Ministry of Health, Guinea-Bissau, and the Swedish Agency for Research Cooperation with Developing Countries (SAREC).

This study was supported in part by the Danish Council for Development Research.

Special thanks are due to Drs M Boal, P Medina, and $C$ da Silva, of the Ministry of Health, Guinea-Bissau, for their interest in our work. We are indebted to Carolina Barbosa, Matarina Co, Manuel Fernandes, Armando Gomes, Joaquim Gomes, Mariano Soares da Gama, Francisco Indi, Joana Lopes, Eugenio Pereira, Angelina da Silva, and Fatima Turé who assisted in the collection of data.

Requests for reprints to: Peter Aaby, Institute of Ethnology and Anthropology, Frederiksholms Kanal 4, DK-1220 Copenhagen K, Denmark.

\section{References}

${ }^{1}$ Guyer B, McBean AM. The epidemiology and control of measles in Yaoundé, Cameroun, 1968-1975. Int J Epidemiol 1981; 10: 263-9.

${ }^{2}$ Davis R. Measles in the tropics and public health practice. Trans Roy Soc Trop Med Hyg 1982; 76: 268-75.
${ }^{3}$ Hopkins DR, Hinman AR, Koplan JP, Lane JM. The case for global measles eradication. Lancet 1982; 1: 1396-98.

${ }^{4}$ Aaby P, Bukh J, Lisse IM, Smits AJ. Overcrowding and intensive exposure as determinants of measles mortality. Am J. Epidemiol 1984; 120: 49-63.

${ }^{5}$ Aaby P, Bukh J, Lisse IM, Smits AJ. Measles vaccination and reduction in child mortality: a community study from Guinea-Bissau. J. Infection 1984; 8: 13-21.

${ }^{6}$ Guyer B. La transmission de la rougeole a Yaoundé. Médecine Tropicale 1976; 36: 451-4.

${ }^{7}$ Grounds JG. Measles in Kenya. J Trop Med Hyg 1964; 67: 169-76.

${ }^{8}$ Glyn-Jones R. Measles vaccine and gamma globulin in the prevention of cross infection with measles in an acute paediatric ward. Central Afr J Med 1972; 18: 4-9.

${ }^{9}$ Savage FMA. A year of measles. Med J Zambia 1967; 1: 67-77.

${ }^{10}$ Wesley A, Coovadia HM, Watson AR. Immunization against measles in children at risk for severe disease. Trans Roy Soc Trop Med Hyg 1979; 73: 710-5.

${ }^{11} \mathrm{Katz} M$, Stiehm ER. Host defense in malnutrition. Pediatrics 1977; 59: 490-5.

${ }^{12}$ Mitus A, Holloway A, Evans AE, Enders JF. Attenuated measles vaccine in children with acute leukemia. Am J Dis Child 1962; 103: 413-8.

${ }^{13}$ Mawhinney. H, Allen IV, Beare JM, et al. Dysgammaglobulinaemia complicated by disseminated measles. Br Med J 1971; 2: 380-1.

${ }^{14}$ McMurray DN, Loomis SA, Casazza LJ, Rey H. Influence of moderate malnutrition on morbidity and antibod response following vaccination with live, attenuated measles virus vaccine. Bull PAHO 1979; 13: 52-7.

${ }^{15}$ Wagstaff LA. A preliminary report on measles and the use of attenuated live measles vaccine in Bantu paediatric hospital practice. S Afr Med J 1969; 664-9.

${ }^{16}$ Ifekwunigwe AE, Grasset N, Glass R, Foster S. Immune response to measles and smallpox vaccinations in malnourished children. Am J Clin Nutr 1980; 33: 621-4kê $\overrightarrow{0}$

${ }^{17}$ Vivell $O$, Lips $G$. Erfahrungen mit de? Masern-Lebendimpfung. Arch Kinderheilk 1968; 176: 156-63.

${ }^{18} \mathrm{Harris}$ MF. The safety of measles vaccine in severe illness. $S$ Afr Med J 1979; 38.

${ }^{19}$ Génécé $E$, Davis $R$. Interruption of local measles transmission by surveillance and containment. Trans Roy Soc Trop Med Hyg 1982; 76: 98.

${ }^{20}$ Aaby P, Bukh J, Lisse IM, et al. Determinants of measles mortality in a rural area of Guinea-Bissau: Crowding, age, and malnutrition. J. Trop Pediatr 1984; 30: 164-8. 